\title{
Study on Strategies of Urban River Environment Improving Based on the Concept of Ecological Infrastructure
}

\author{
$\mathrm{Wu}$ Tao \\ College of Horticulture, Nanjing Agriculture University, Nanjing, China, 210095
}

\begin{abstract}
The ecological infrastructure is a type of urban infrastructure which provide comfortable, healthy, efficient, convenient for the social production and living, and coexist harmoniously with the natural. Urban ecological infrastructure is the important foundation of the city sustainable development, and also an important guarantee for the construction of the ecological city. In the rapid urbanization, ensuring structure and function integrity of the urban ecological infrastructure is particularly important, urban river environment improvement is a part of content of greenway construction in ecological infrastructure development, and has important significance to improve the city ecosystem function, catalyze urban region renewal, inherit urban history and culture, and provide recreational space. Environmental transformation of the urban river need appropriate engineering measures and ecological strategies, including water conservancy and hydrology regulation, ecological environment reconstruction, pedestrian and vehicle transportation arrangement, humanity space strategy, and ultimately ensure the safety, health and sustainable development of river ecological system.
\end{abstract}

KEYWORD: Ecological infrastructure; Greenway; Urban river; Engineering measures; Ecological strategy

\section{INTRODUCTION}

Ecological infrastructure (referred to as EI) is a natural system of city daily depends on, it is a key land spatial pattern to maintain the life safety and health, and the basic guarantee of sustainable ecosystem services for city and residents[1]. These ecological services include providing fresh air, clean water, safe refuge, sports, leisure, entertainment, aesthetic, cultural and education[2]. However, the current city civilization are generally established on the intensive gray infrastructure[3], which includes large road system arranged in a crisscross pattern, huge pipeline system, large-scale sewage treatment plant, urban landfill and so on. Urban operation depends on these unnatural artificial systems and artificial energies, and the huge economic, social and ecological problems have arisen.

\section{THE FUNCTIONS OF URBAN RIVER ECOLOGICAL INFRASTRUCTURE}

As the corridor space of ecological infrastructure, the river provide the functions of rain flood drainage and storage, sewage discharge and purifying, aquatic animals and plants breeding, biodiversity maintenance, providing green space, which is the kidney(water) and ling(waterfront green space) of city[4]. The river provides the educational, aesthetics and recreational space for residents, but also the carrier of culture inheritance of city history[5]. The healthy water nourishes the city development, and the birthplaces of ancient civilization are all benefit from the river, many ancient cities flourished because of water.

The river of current city reflects all aspects of city appearance, also recorded and witnessed the rise and fall of the area the river flows through. With the rapid development of the city, the environment of urban river faced unprecedented pressure, including that direct discharge of sewage caused the decline of water qualities, insufficient channel cross-sectional caused city flood retention, the embankment collapsed and damaged, and waterfront landscape cluttered and lack of characteristics etc[6]. 
3 ENGINEERING MEASURES AND ECOLOGICAL STRATEGY OF RIVER ENVIRONMENT IMPROVEMENT

Siyang is located by the famous Beijing Hangzhou Grand Canal River of China, Baohe flow through the entire city for $11.2 \mathrm{~km}$, and width of this river is about $20 \mathrm{~m}$ to $100 \mathrm{~m}$, which covers an area of about 30 hectares and 200,000 people benefited from it. Taking water from the Beijing Hangzhou Grand Canal, Baohe river floe through commercial center district, inner city residential areas, suburban residential areas, industrial areas, suburban green space, and finally influx into the city peripheral channel of Sitang river (Figure 1).

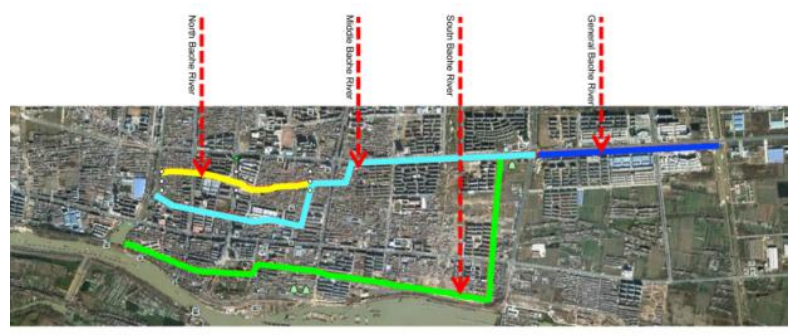

Figure 1. Master plan of Baohe river

The environment of main urban area Baohe River passing through has deteriorated seriously, sewage of public toilet and dwelling is directly discharged into the river, embankment retaining wall is full of holes out flowing black water with foul smelling; whether in commercial or residential area piles of garbage float on the water surface. In order to hide ugly river view, dense shrubs are planted on both sides of the river, with concrete pergola climbed with Wisteria covering the river. Even more, some section was directly covered with concrete ground and becomes underground river. The retaining wall on both sides of Baohe river are old and simple, some of them have been broken and unsafe, the river channel was narrow and flood storage capacity is insufficient, so there is a risk of inner city flooding. The retaining wall in lower reaches is up t0 $3 \mathrm{~m}$ high, it has poor hydrophilic and accompany some safety problems. Overall, as a part city ecological infrastructure, Baohe River almost did not play its due role in the ecological and social service, and need to be improved by some engineering measures and ecological strategies.

In view of the above issues, Baohe waterfront planning created hydrophilic public space by using different elevation approach, combined with the city water conservancy, integrated storm water management, restored waterfront vegetation; and it combined local history and culture, regenerated city waterfront arts, optimized waterfront space and land use, stimulated and catalyzed health city development. The planning strategy follows the following aspects:

\subsection{Water resource treatment}

Water resource should maintain a certain cleanness, and pollution water are limited to discharge into the city river, otherwise ecological purification treatment should be taken[7]. For the water with large impurities and sand, it should be taken some precipitation treatment. Water resource of Baohe river come from Beijing Hangzhou Grand Canal, flowing into city through the Sishui River. In order to prevent pollution at the source, sewage pipes and sewage pool were buried nearby water source, a garbage transfer station was built to collect the domestic sewage and solid waste.

Because of large sediment concentration of the Grande Canal and busy shipping vessels, the water was turbid. Sishui river is an irrigating river and the water flow is urgent, which result in many sedimentary sand stirring and suspension, so the water sources quality of Baohe have a yellow turbid appearance. In order to realize the goal of clean water flowing into the city, sedimentation tank should be built at the source to purify water through the engineering measures. Sedimentation tank with inclined tube principle, it will be effective in making these micro particle of water sediment in the bottom of the pool. Precipitated sand will be removed out of the tank by pump and be recycled for industry use (Figure 2,3).

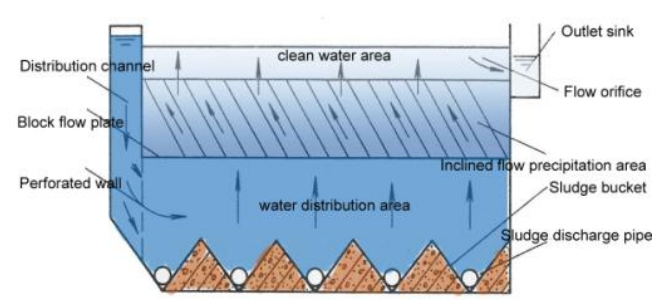

Figure 2.Schematic diagram of inclined tube sedimentation tank

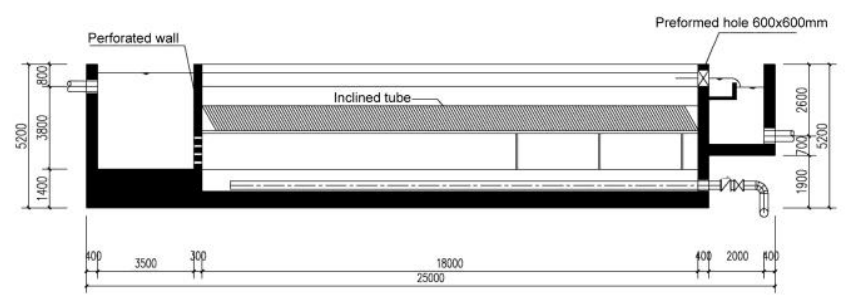

Figure 3.Section of Sedimentation tank

The precipitated water will stay for a long time in the source lake, taking further precipitation which makes the upper reaches of the river water clear. In order to eliminating organic impurities and microorganism of water, many ecological islands were set in the lake to make water flow slowly, which is conductive to the sand deposition, but also providing biological reaction time of organic matter decomposition. After engineering treatment and 
ecological degradation, the river water has basically become clear.

\subsection{Rainwater and sewage discharge separately}

In view of the sewage directly into the river, the best method is to use the management system of rainwater and sewage discharge separately. Through urban infrastructure renewal of surrounding area, the sewage pipes were laid out on both sides of the river to intercept sewage and truncate the external pollution sources (Figure 4). Rainwater will also be collected into storm sewer and discharge into the river after simple treatment. The daily garbage will be collected into garbage transfer station and carried away the waterfront outside the region regularly. The garbage blowing by wind or human discard into the water will be intercepted by metal mesh in the river, and be regular cleaned.

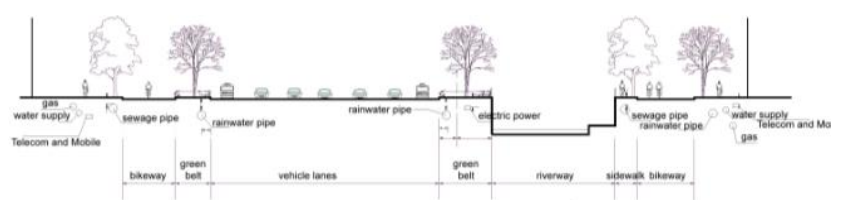

Figure 4.Sketch map of diversion of rainwater and sewage and municipal road riverside

\subsection{Water level control}

Control of water level between upstream and downstream realized by the overflow weir engineering, which creates both waterfall and splash landscape, and keep the proper water level effectively.

Because the upstream of Baohe River has little flood pressure, the upstream water level was raised appropriately, which provides the chance to create rich waterfall landscape in the downstream. The elevation difference is about $2.55 \mathrm{~m}$ between the upstream and downstream, in order to ensure graceful river landscape, the water level was divided into 7 drop to store water hierarchically (Figure 5).

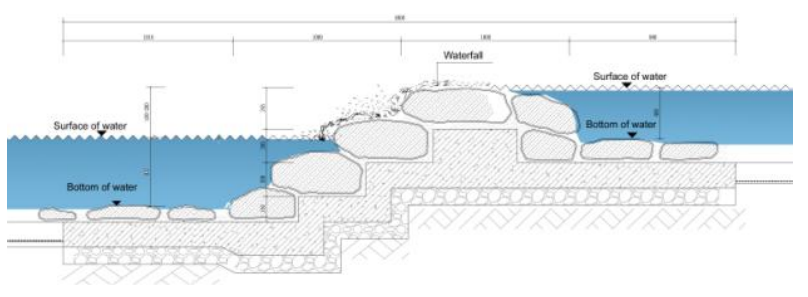

Figure 5.Water level control

\subsection{Revetment reconstruction}

The blunt and humble retaining wall has beautified through elevation treatment and landscaping. The plan enrich the style of revetment and water shoreline shape through the path along the water, hydrophilic platform and steps and other landscape forms, which enables people proximity to water and provides multi-level waterfront leisure space[8] (Figure 6).

Original revetment of Baohe river was mortared rubble, and the foundation of revetment fractured by the long-term erosion. The plan promoted concrete revetment and rebuilding the foundation to meet the requirements of city water conservancy, and adopted second level or third level platform, so that people can be close to the surface of the water. In order to decorate downstream towering rigid wall, planter and scenic stone were fixed in the base of retaining wall and some water tolerance plants were planted in it, which softened the hard landscape on both sides (Figure 7).

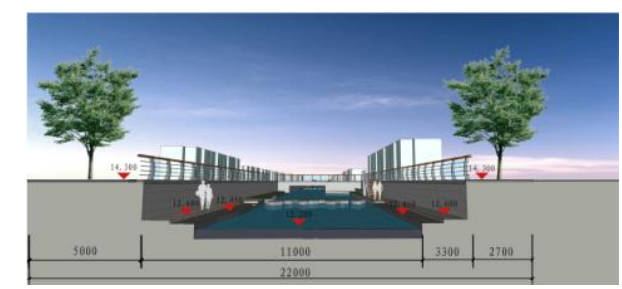

Figure 6.The designed revetment

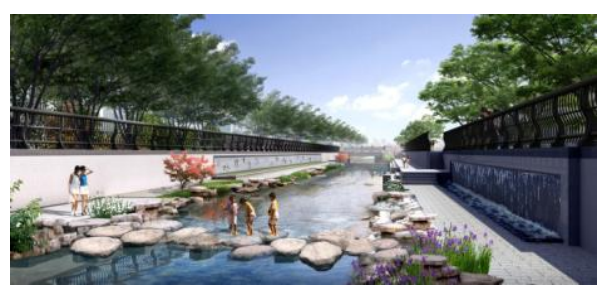

Figure 7.Ecological river landscape

\subsection{Resilient green river strategy}

The current city is faced with stormwater sewer pressure, which always resulting incity flooding, the river should play a greater role in flood storage and detention[9]. On the one hand, the river crosssection area should be enlarged as possible, and make waterfront green space and trails sink into river bed space: a which does not affect the use of people, but expanding the river section and improving the capacity of flood storage; on the other hand, enlarging some nodes form a series of lakes every $500-600 \mathrm{~m}$, the lakes played a "green sponge" role - the resilient control of water storage capacity was realized by water level adjustment. In addition to improve the flood detention capacity, the expanding regions also provide ample riverfront green spaces and recreational facilities. 
Compared the plane alignment design of Baohe with original one, the river bed were widen than before, and internal space increased, together with several beautiful landscape nodes, the river likes an emerald necklace across the city. Baohe river communicated various regional by its greenway formal, and provided adequate ecological and leisure services for surrounding residents (Figure 8).

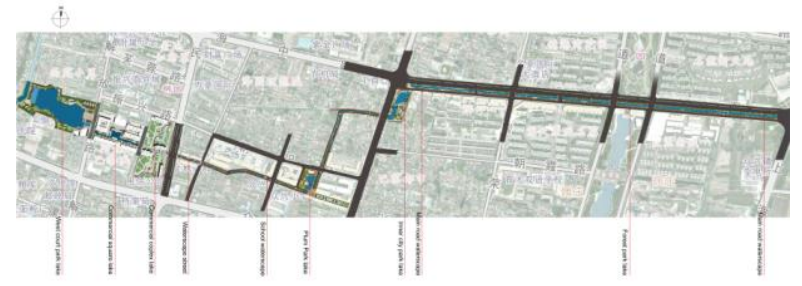

Figure 8.River plane form (swollen "green sponge" flood detention area)

The method of amplifying river space provides a safety guarantee for city water environment, and at the same time the lake wetland is a purification area for the storm water runoff. These natural waterways and lake wetlands have become the habitat of local native wetland plants and birds.

\subsection{Low maintenance and Sustainability}

City public space, especially the large scale city waterfront green space, should try to reduce financial and human input of maintenance, and achieve sustainable ecological succession[10]. The low maintenance of native shrubs and hygrophyte can effectively reduce water supply and economic costs, such as the perennial and self-sow flowers, and ornamental grasses. The contrast between "messy" nature and low cost scrambled waterfront walk design, become an artful daily landscape.

\subsection{Pleasant low traffic system}

In order to improve the social service function of the river, connectivity and comfort should be fully considered all through both sides of the river. The slow traffic system of water byway created a convenient daily traffic, and the leisure corridor provide a continuous waterfront experience and sports and fitness space for people[11].

The scenic water byway all through the river space, completely conform to the river and the surrounding land elevation. In addition, sidewalks and bicycle lanes are arranged along the riverside greenway, and every $300 \mathrm{~m}$ set a bridge across the river. These roads and bridges are connections of residential and commercial zone, which form a very convenient traffic system and completely changed originally isolation condition. Baohe waterfront perfected traffic system and humanity space and promoted regional renewal. The original business district become more vigor, shabby isolation "village in the inner city" showed signs of life, daily waterfront leisure activity increased, and the land appreciation inspired more diversified land use. It can be said that the transformation of this river is a comprehensive project of city water conservation, municipal transportation, land use, landscape engineering.

\subsection{Rich leisure facilities and cultural attractions}

City river often carry on the long history and culture of the city, during the renewal of waterfront environment, we should fully excavate traditional culture, reproduce the historical memory, and create a strong cultural atmosphere in the living environment of the city. In order to facilitate people access, waterfront public space should provide a variety of recreational facilities and venues, such as plazas, music fountain, seat, fitness facilities, pavilions, public toilets, sale stand, parking lots and other services; landscape wall, cultural promenade, sculpture, art pieces and other cultural facilities; guardrail, landscape bridge, parterre and other enclosure; signs, logo, maps and other facilities. Baohe river was built over 400 years ago, which is the artery and vein of the city, witnessed all the things that the city have been through. Baohe river waterfront landscape design concept take "water culture", ancient monument culture and Baohe memory as the main line, designed the cultural attraction of Baohe memory hall, park teahouse, ancient Baohe inscriptions, Merit wall.

\subsection{Landscape guiding the urbanization}

In the process of provision of high quality ecological infrastructure, waterfront greenway can be used as catalyst for regional renewal, land utilization and city texture change. Due to environmental improvement of Baohe waterfront, commercial complex were introduced into the city business district, the old "village in the inner city" were converted into a high-quality development, and suburban section was envisioned to construct high density residential area. After the river greenway was built, an enormous amount of new housing development investment has been attracted and completely transformed the urban morphology of the city.

\section{SUMMARY}

Environmental transformation of city river has great significance for the improvement of river ecological infrastructure: perfecting city ecological system, improvement regional ecological environment, catalytic city renewal and healthy development, 
inheriting city historical culture, providing public entertainment space.

\section{REFERENCES}

[1] Ma Shijun, Wang Rusong. The social-economic-natural complex ecosystem. Acta Ecologica Sinica.1984, 4(1):19.

[2] Li Feng, Wang Rusong, Zhao Dan. Urban ecological infrastructure based on ecosystem services: status, problems and perspectives. Acta Ecological Sinica. 2014, 1:190-200

[3] Li Junfeng, Liu Jia, Wu jingxiong. Research on urban river landscape planning based on concept of green infrastructure. Journal of Hefei University of Technology. 2011, 2:105-110

[4] Zhu Qiang, Liu Hailong. Review of greenway planning research development. City Problem. 2006, 5:11-16

[5] Zhou Yan, Fan Lei. Protection and utilization of urban river landscape from the view of historical cultural landscape regeneration. Journal of Anhui Agriculture Science. 2013, 41(25):10372-10373

[6] Wu Lin. Research of city river regulation engineer. Heilongjiang Science Technology of Water Conservancy. 2013, 9:255-256

[7] Li Ming, Cai Ye, Liu Qide, et al. Study advance of ecological restoration technique for urban stream in China. Environ Health. 2009, 9:837-839

[8] Su Chenyang. Analysis of city river landscape pattern. Chinese Landscape Architecture. Vol.15, 1999, 1:8-11.

[9] Bai Xiantai. Study on optimal operation rules of city storm water system. Advances in Water Science. Vol.8, 1997, 12:341-347

[10] Le Maohua, Liu Jun, Hu Heping. Ecological restoration technology of Shenzhen river. China Rural Water and Hydropower. 2012, 2:25-28

[11] Yu Kongjian, Zhang Yuan, Liu Yunqian. Prior to ecological infrastructure: Ecological design of Wuhan Wulijie ecological city. Beijing Planning and Construction.2013, 6: 48-53 